\title{
Correlations between the Qualitative and Quantitative Characters of Some Plum Varieties, after Chemical Thinning
}

\author{
Andreea Flavia TRIPON ${ }^{1 *}$, Viorel MITRE ${ }^{1}$, Ioana MITRE ${ }^{1}$, Ioana MITRE jr. ${ }^{1}$, Monica PAL ${ }^{1}$ \\ Department of Fruit growing, University of Agricultural Sciences and Veterinary Medicine, Cluj-Napoca, \\ Romania \\ *)Corresponding author, e-mail: andreeaflavia_tripon@yahoo.com
}

BulletinUASVM Horticulture 73(2) / 2016

Print ISSN 1843-5254, Electronic ISSN 1843-5394

DOI:10.15835/buasvmcn-hort:11952

\begin{abstract}
The analysis of the existing relations between characters is of a great importance because it allows the selection of genotypes that simultaneously has a combination of several useful characters. Values close to +1 indicate a strong positive correlation; those around -1 indicate a significant negative correlation and values close to zero indicate that between those two characters doesn't exist any correlation. Between the analysed characters in this experiment, there are both positive and negative correlations. The experience was carried out between the years 2012 and 2014. The study took place in Călacea orchard where 4 plum varieties were analyzed. Determinations regarding the influence of thinning have been made for these varieties on: fruit firmness $\left(\mathrm{Kgf} / \mathrm{cm}^{2}\right)$, fruit weight (g), dry matter (\% DM) and total acidity (\% malic acid). There was a positive correlation between firmness (Kgf/ $\left.\mathrm{cm}^{2}\right)$ and fruit weight $(\mathrm{g})$; the coefficient of correlation being significant $(\mathrm{r}=0,438)$. The correlation between the solid content (\% SC) and fruit weight ( $\mathrm{g}$ ) shows a strong dependence between the two characters, the coefficient of correlation being very significant $(\mathrm{r}=0.706)$. Between the total acidity (\% malic acid) and fruit weight $(\mathrm{g})$, there is a strong dependency, the coefficient of correlation being significantly negative $(r=-0.652)$.
\end{abstract}

Keywords: concentration, diameter, fruit quality, thinning flowers

\section{Introduction}

A wide load of fruit tree leads to small-sized fruit production and a lower quality, consuming the reserves and reducing the trees' resistance to extreme temperatures. The fruit load thinning of the fruit trees is a very necessary task and has the goal to improve the size and quality of the fruit (Basak, 2006; Meland et al., 2010).

\section{Aims and objectives}

The aim of this study was to investigate the relations between fruit firmness, solid content, total acidity and fruit weight.

\section{Materials and methods}

This research was carried out between 2012 and 2014. The experiment took place at the Călacea orchard where 4 plum varieties were examined
('Tuleu timpuriu', 'Stanley', 'Gras Ameliorat' and 'Anna Spath'). Determinations regarding the influence of thinning have been made for these varieties on: fruit firmness $\left(\mathrm{Kgf} / \mathrm{cm}^{2}\right)$, fruit weight (g), dry matter (\% DM) and total acidity (\% malic acid). From each tree 100 fruits were harvested and analyzed. The results were processed by ANOVA test.

\section{Results and Discussion}

The results show that there is a positive correlation between firmness $\left(\mathrm{Kgf} / \mathrm{cm}^{2}\right)$ and fruit weight $(\mathrm{g})$, the correlation coefficient being significant $(r=0,438)$. The more fruit firmness is higher; the greater the fruit weight is (Fig. 1).

The correlation between solids content (\% SC) and fruit weight ( $\mathrm{g}$ ) shows a strong dependence between the two characters, the correlation 


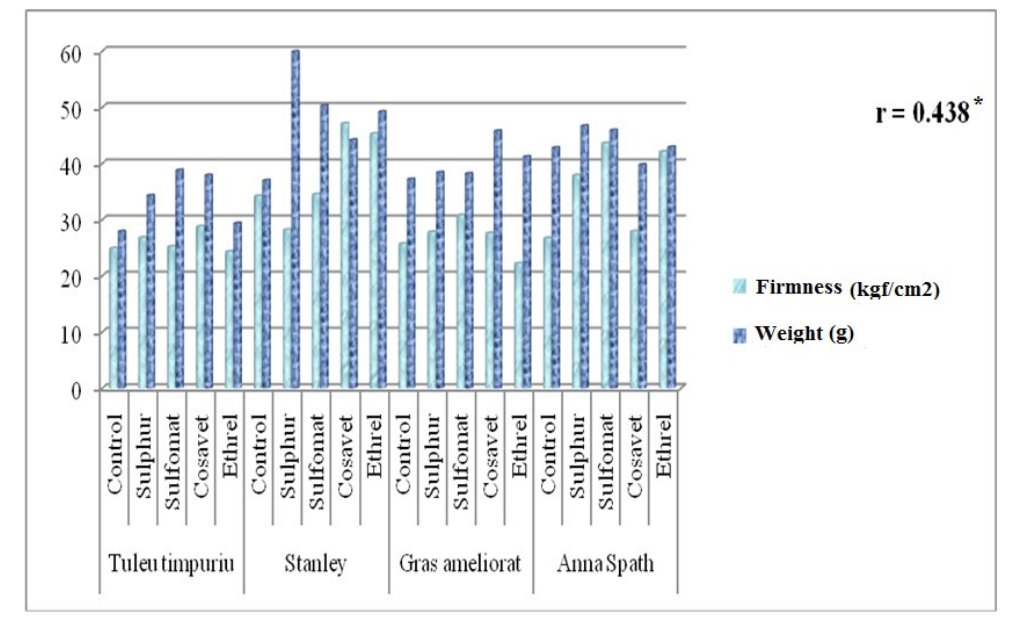

Fig. 1. Correlations between fruit firmness and fruit weight of the plum cultivars

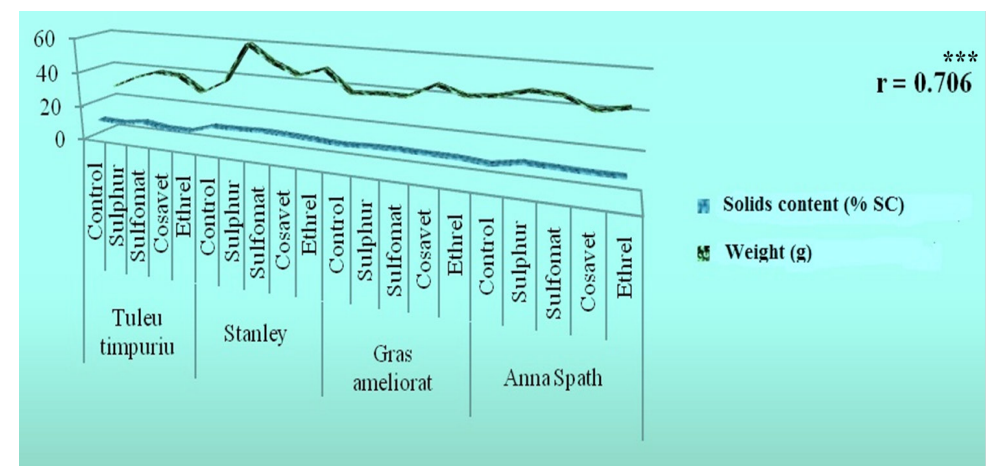

Fig. 2. Correlations between dry matter content and fruit weight of the plum cultivars

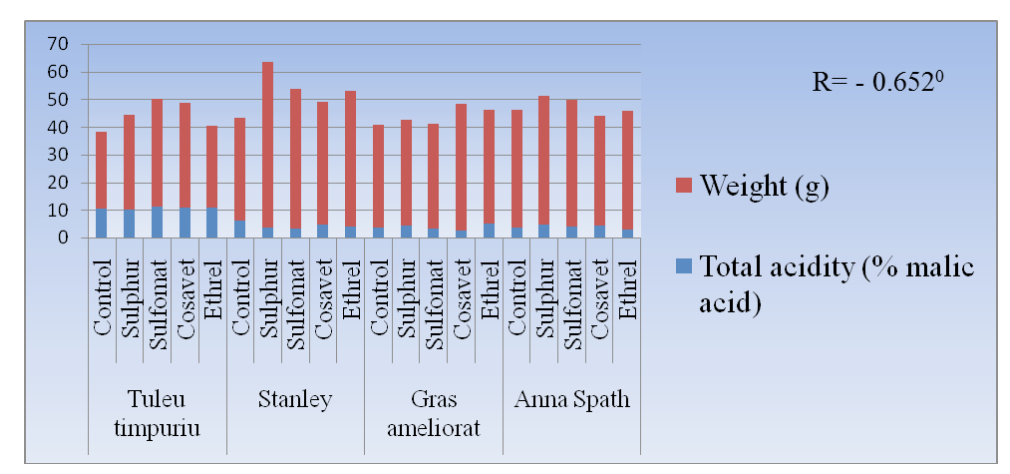

Fig. 3. The correlation between total acidity and fruits weight of plum cultivars, in Călacea experimental field

coefficient being very significant $(\mathrm{r}=0.706)$. The more fruit weight is higher, the greater the solid content (\% SC) is (Fig. 2).

Because of chemical thinning the fruits gained more weight, therefore we can affirm that to the same extent these treatments increase the solid content as well. Between total acidity (\% malic acid) and fruit weight (g), there is a strong dependency, the correlation coefficient being significantly negative $(r=-0.652)$.

As long as the total acid content (\% malic acid) was higher, the fruit weight (g) was lower. It can be concluded that there is a direct negative relation between the two characters (Fig. 3). In the case of smaller-sized fruits higher acidity content was recorded. Moreover, the flower will induce 
chemical thinning will decrease the organic acid content.

\section{Conclusion}

After analysing the qualitative and quantitative characters of these 4 plum varieties, it has been found that there is a close relation between the qualitative and quantitative characters; as long as the qualitative values are high, the quantitative values are low.

\section{REFERENCES}

1. Meland M and Birken E (2010). Ethephon as a blossom and fruitlet thinner affects crop load, fruit weight and fruit quality of the european plum cultivar, Jubileum', ISHS Acta Hortic., 884: XI International Symposium on Plant Bioregulators in Fruit Production.

2. Basak A (2006). Search for safe and efficient methods of chemical thinning by improving absorption of preparations and their subsequent use, ISHS Acta Hortic., 727: X International Symposium on Plant Bioregulators in Fruit Production. 